\title{
Costs of hospital-acquired infection for patients hospitalized in intensive care unit of an Iranian referral hospital
}

\author{
Farzad Soleymani ${ }^{1}$, Hossein Safari palangi*2, Ali Sarabi Asiabar ${ }^{2}$, Abbasali Keshtkar $^{3}$, Mohsen Mohammadi ${ }^{4}$, \\ Ali Akbari Sari ${ }^{1}$, Ali Saber ${ }^{5}$
}

Received: 12 July 2017

Published: 6 Aug 2018

\begin{abstract}
Background: Hospital infections have affected millions of people around the world and are considered as one of the most important issues related to patient safety. Therefore, this study was conducted to estimate the extra costs caused by hospital-acquired infections in hospitals.

Methods: This retrospective cohort study was conducted in Tehran province, Iran, in 2017. Medical records of 235 patients hospitalized in one of Tehran hospitals were reviewed for the study. They were divided into case (90 patients) and control (145 patients) groups. Data were analyzed using SPSS and STATA software.

Results: Results revealed no significant relationship between age and gender with the incidence of nosocomial infection ( $p>0.05$ ). However, the chance of nosocomial infection is most affected by length of hospital stay and costs paid by patients. Moreover, nosocomial infection increases the length of hospital stay up to 25 days. Our results revealed that the mean \pm SD hospital stay of infected and non-infected patients were $15.8 \pm 17.2$ and $40.8 \pm 19.1$ days, respectively. Furthermore, the total cost of patients without any hospital infection was $2451 \pm 3098$ USD (83 $674480 \pm 105765500$ Rials). On the other hand, the cost for infected patients was $3264 \pm 6078$ USD (207 $497500 \pm 111430700$ Rials).

Conclusion: Hospital-acquired infections can impose great costs on both patients and the health system. The results of this study indicated the importance of taking specific measures for infection control in hospitals.
\end{abstract}

Keywords: Hospital-acquired infection, Hospital costs, Medical records, Iran

Copyright $₫$ Iran University of Medical Sciences

Cite this article as: Soleymani F, Safari palangi H, Sarabi Asiabar A, Keshtkar A, Mohammadi M, Akbari Sari A, Saber A. Costs of hospitalacquired infection for patients hospitalized in intensive care unit of an Iranian referral hospital. Med J Islam Repub Iran. $2018(6$ Aug);32:67. https://doi.org/10.14196/mjiri.32.67

\section{Introduction}

Hospitals are considered as the most important entities in provision of health services. However, these services may not be equally delivered to the public(1). Small area variation (SAV) analysis is a tool adopted by health services researchers to define how rates of health care usage and events differ depending on various geographic areas. On the other hand, such services need to be of high quality

Corresponding author: Dr Hossein Safari Palangi, hossein.comely@gmail.com

1. Department of Health Management and Economics, School of Public Health, Tehran University of Medical Sciences, Tehran, Iran.

2. Health Management and Economics Research Center, Iran University of Medical Sciences, Tehran, Iran.

3. Department of Health Sciences Education Development, School of Public Health, Tehran University of Medical Sciences, Tehran, Iran.

4. Kermanshah University of Medical Sciences, Kermanshah, Iran.

5. School of Medicine, Kashan University of Medical Sciences, Kashan, Iran. and away from any kind of hospital side effects or infections $(2,3)$. Prevention of hospital-acquired infections with respect to health, economic, and social aspects has caught the attention of experts for years; and they have been trying tirelessly to find proper solutions for solving this problem (4). Luckily, these infections are, to a large extent, preventable (5). For instance, in case of England's

$\uparrow$ What is "already known" in this topic:

Hospital infections have affected millions of people around the world and are considered as one of the most important issues related to patient safety.

\section{$\rightarrow$ What this article adds:}

Nosocomial infection increases the length of hospital stay up to 25 days. In addition, in this study, it was found that infected and non-infected patients stayed $15.8 \pm 17.2$ and $40.8 \pm 19.1$ days in the hospital, respectively. Furthermore, the total cost of patients without any hospital infection was $2451 \pm 3098$ USD (83 $674480 \pm 105765500$ Rials) and that of the infected patients

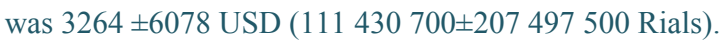


context, approximately one third of these infections are likely to be preventable; such a reduction could save almost $£ 150000000$ for National Health Service (6). Nonetheless, such infections impose high costs on public health systems. However, an exact estimation of costs caused by health-acquired infections requires an assessment of efficiency of other infection control actions, which is usually difficult.

Even if hospital mangers implement the required actions to reduce the costs, they still cannot control all the costs. It seems that less use of resources is the only choice left for decreasing such costs in hospitals. On the surface, reducing nosocomial infections is one of the proven methods for decreasing the use of resources. On the other hand, fewer infections would improve patients' health conditions as well (7).

In most of the health systems, such as hospitals, rehabilitation centers, and long-term care centers, health careassociated infections have been a hidden and crosssectional issue; and no country or organization can claim that they have entirely solved it $(8,9)$. Because these infections are considered to be contagious and no patient, hospital, or health system is immunized against them, they impose considerable costs on these entities (10).

Nosocomial infections are important for the following reasons: mortality and sickness of patients, increased length of hospital stay, and increased hospital costs due to long length of stay and extra therapeutic-diagnostic services $(11,12)$. Hospital infections have affected millions of people around the world and are considered as one of the most important issues related to patient safety. They account for almost $5 \%$ to $10 \%$ of acute care admissions in industrial countries. The incidence rate of such infections rises up to 2 to 20 times for developing countries, and the rate of patients with such infections is $25 \%$ more (13). According to international studies, the prevalence of health care-associated infection (HCAI) for patients living in high-income countries is approximately 7.6\%. Moreover, European Center for Disease Prevention and Control (ECDC) has estimated that annually about 4131000 patients get 4544.100 episodes of health care-associated infections in Europe. In 2002, about $4.5 \%$ of people in the U.S. had HCAI, which is 9.3 infections per 1000 patientday. The systematic review of the literature showed no clear picture of HCAI load in developing countries. There was only some general information in some regions of the countries, and this information was not even accessible in $66 \%$ of these countries. In such countries, the rate of HCAI was a lot higher than developed countries, as its incidence at hospital level was reported to be $10.1 \%$, but the entire statistics of infection prevalence was reported to be $8.5 \%$ to $15.5 \%$ (14).

Centers for Disease Prevention and Control around the world estimated that about 2 million people suffer from nosocomial infections annually and approximately 100 000 are lost to these infections. Such infections impose $\$ 4.5$ billion extra costs on health care systems yearly (15). According to $\mathrm{WHO}$, intensive care units, along with orthopedic and surgical wards, have the highest prevalence rate of hospital infections (16). In the United States, the incidence of nosocomial infections is around 2 million per year, out of which 500000 cases happen in intensive care units. This means that about one fourth of such infections take place in ICUs, indicating the importance of this ward in the matter of hospital infections (17).

To date, there has been no strong study on nosocomial infection costs in the context of Iran; moreover, health authorities have not paid enough attention to this issue. Thus, this study was conducted to estimate the extra costs caused by such infections in hospitals. The results of the present study will shed light on the importance of nosocomial infections and the effect they have on hospital expenditures.

\section{Methods}

\section{Data}

This retrospective cohort study was conducted in 2017 in Tehran province, Iran. This study was approved by the Ethics Committee of Tehran University of Medical Sciences, TUMS (ethics code: 9111119006-1). Although samples were selected using census method, those medical records that were incomplete or out of reach were excluded from the study. Because there were very few hospitals with equipped intensive care units, we needed to select those hospitals that, firstly, had intensive care unit and, secondly, whose active beds were occupied.

Considering the above-mentioned point, we selected Imam Khomeini hospital, which is the largest hospital in the country and in the Mediterranean area. All medical records of patients hospitalized in this hospital in 2015 were reviewed. Moreover, one of the other methods to compare nosocomial infection costs was to use the data gathered from several hospitals either in the national or regional level. Moreover, we calculated per capita cost through dividing the total hospital costs by the number of hospitalized patients.

All hospitals may face with a phenomenon called "small area variation (SAV)" in delivering medical services; therefore, we can use the same logic for studying hospitals, which consist of doctors and other medical staff. This perspective can be implemented and recommended. However, its implementation requires researchers to use precise and complicated statistical methods and great deal of time and financial resources due to the difference in data collection techniques and quality of hospital services and the difference in the admission policies of hospitals. Thus, it was decided to use the data of only 1 hospital to extract nosocomial costs in intensive care units, and this approach was by no means impeccable.

One of the drawbacks of such approach is that the data gathered from only 1 hospital can result in bias. In other words, those patients who refer to that certain hospital may have referred for a common medical reason or problem, so we have the same risk factors for all of them; and if they are studied, the external validity of the study will weaken and the generalizability of the results will be affected as well. Therefore, considering the problems associated with both approaches and the limitations of the study, we decided to use data of only 1 hospital. However, we tried to reduce the problems which normally occur 
during the data collection process, so we could have the least bias in the study. As mentioned by other studies, the severity and treatment of the diseases are 2 factors that increase nosocomial costs in intensive care units. However, we needed a strategy to match patients using their financial and clinical data to maintain a balance between case and control groups, select the control group accurately, and exclude patients with vague and unmatchable criteria and indexes. Patients were studied for their medical costs, length of hospital stay, severity of their disease, and presence or non-presence of hospital infection. Most of the related studies have focused on ICU patients who present a group of patients with exceedingly high severity and hospital cost. Furthermore, the costs of providing care for patients with nosocomial infections were compared with the costs of providing medical services for those without any sign of infection.

We needed to study the case group before the control group. To this end, the list of all patients with nosocomial infection was extracted from the hospital infection record system. Then, using medical record number, name, age of the patient, and their hospitalized ward, their records were extracted from the medical record department of the hospital. Next, cases of infection, hospital bill, lab information, and the ward where the patient was hospitalized and ICU checklists were carefully studied. An ICU nurse was asked to extract data related to vital signs and other points listed in APACHE.

From 189 medical records taken from the hospital's medical record department, 90 were complete and useful for the objective of the study. Other medical records were excluded due to having incomplete information about hospital bill and not including all patients' lab and other medical reports. In the second step, a control group was selected for the study. To choose the patients of this group, information of patients who were hospitalized in the general intensive care unit of the hospital in 2013 was obtained from the medical record department of the hospital. These data had to be adjusted; patients with less than 48-hour hospitalization were excluded from the study, as they could not get any hospital infection. Then, the patients who were hospitalized in the same unit and had hospital infection were ruled out because they had been considered once before in the study. Next, we asked for other remaining medical records from the medical record department of the hospital for both the case and control groups. Out of 483 medical records, 145 were reviewed.

\section{Statistical analysis}

Data for both groups were entered into Excel software and analyzed using SPSS and STATA software. We also used regression models to show the effect of variables on nosocomial infection.

\section{Results}

No significant relationship was found between age and gender with the incidence of nosocomial infection. On the other hand, the chance of nosocomial infection was most affected by length of hospital stay and costs paid by patients (Table 1). In other words, the more the length of hospital stay in ICU and the more the hospital costs of patients, the more the chance of getting hospital infection (Table 1).

Data analyzed using chi-square test revealed no correlation between nosocomial infection with age and severity of disease as risk factors ( $p>0.005$, odds ratio $>1)$. However, a significant relationship was found between nosocomial infection with length of stay in ICU $(p<0.005$, odds ratio $>1$ ) (Table 2).

Based on the findings of univariate and multivariate regression, there was no significant correlation among variables of age, gender, and severity of disease with nosocomial infection ( $p>0.005$, Odds Ratio $>1)$. On the contrary, hospitalization of patients in ICU had a significant correlation with having nosocomial infection $(\mathrm{p}<0.005$, Odds Ratio $>1$ ). Patients with longer length of hospitalization were infected 1.12 times more than other patients although having the same severity of disease.

In addition, the results of logistic regression indicated that severity of disease affects the incidence of any kind of hospital infection. Patients with longer ICU stay were 1.22 times more likely to get hospital infection despite having the same severity of disease.

Moreover, logistic regression model was applied to determine the effect of APACHE and total length of stay variables. Results showed that total length of stay had a significant effect on getting nosocomial infection. In other words, total length of stay for the infected patients was

Table 1. Background variables along with important outcomes of hospitalized patients by their incidence of nosocomial infection

\begin{tabular}{|c|c|c|c|c|c|}
\hline Variable & $\begin{array}{l}\text { Patients with HAI } \\
(\mathrm{N}=90)\end{array}$ & $\begin{array}{l}\text { Patients without HAI } \\
\qquad(\mathrm{N}=145)\end{array}$ & $\begin{array}{l}\text { Total number of patients } \\
\qquad(\mathrm{N}=235)\end{array}$ & Test statistic & $\mathrm{p}$ \\
\hline Age (year) & $56.4 \pm 20.8$ & $55.8 \pm 19.4$ & $56.1 \pm 19.9$ & $\mathrm{~T}=0.23$ & 0.82 \\
\hline Gender (male) & $53(58.9 \%)$ & $79(54.5 \%)$ & $132(56.2 \%)$ & $\mathrm{Chi}^{2}=0.44$ & 0.51 \\
\hline $\begin{array}{l}\text { Total length of } \\
\text { stay (day) }\end{array}$ & $35.9 \pm 22.8$ & $11.0 \pm 9.8$ & $20.6 \pm 20.1$ & $\mathrm{~T}=9.8^{* *}$ & $<0.001$ \\
\hline $\begin{array}{l}\text { ICU length of } \\
\text { stay (day) }\end{array}$ & $27.5 \pm 22.4$ & $6.0 \pm 5.7$ & $14.2 \pm 17.9$ & $\mathrm{~T}=8.92$ & $<0.001$ \\
\hline Dead cases & $38(42.2 \%)$ & $83(57.2 \%)$ & $121(51.5 \%)$ & $\mathrm{Chi}^{2}=5.01^{*}$ & 0.03 \\
\hline APACHE & $62.25 \pm 12.24$ & $58.5 \pm 22.0$ & $60.7 \pm 21.3$ & $\mathrm{~T}=1.67$ & 0.1 \\
\hline \multicolumn{6}{|l|}{ Score } \\
\hline $\begin{array}{l}\text { Total charges } \\
\text { (USD) }\end{array}$ & $\begin{array}{c}5330 \pm 3790 \\
(181956287 \pm 129404126 \text { Rials })\end{array}$ & $\begin{array}{c}181.5 \pm 2337 \\
(61099798 \pm 79797001 \text { Rials })\end{array}$ & $\begin{array}{c}3145 \pm 3435 \\
(107385262 \pm 117276560 \text { Rials })\end{array}$ & $\mathrm{T}=7.97^{* *}$ & $<0.001$ \\
\hline $\begin{array}{l}\text { Per capita } \\
\text { charges (USD) }\end{array}$ & $\begin{array}{c}151 \pm 39 \\
(5149084 \pm 1342592 \text { Rials })\end{array}$ & $\begin{array}{c}17661 \pm 260.5 \\
(6294279 \pm 8894963 \text { Rials }) \\
\end{array}$ & $\begin{array}{c}14896 \pm 206.4 \\
(5855694 \pm 7048849 \text { Rials })\end{array}$ & $\mathrm{T}=$ & $<0.001$ \\
\hline
\end{tabular}


Hospital-acquired infection in patients hospitalized in intensive care unit

\begin{tabular}{|c|c|c|c|c|c|}
\hline Variable & Category & $\begin{array}{l}\text { Patients with HAI } \\
(\mathrm{N}=90)\end{array}$ & $\begin{array}{l}\text { Patients without HAI } \\
\qquad(\mathrm{N}=145)\end{array}$ & $\begin{array}{l}\text { Odds Ratio } \\
(\mathrm{CI}=95 \%)\end{array}$ & $\mathrm{p}$ \\
\hline Gender(male) & & $37 / 53$ & $66 / 79$ & $0.84(0.49-1.42)$ & 0.51 \\
\hline \multirow{6}{*}{ Age group (year) } & $0-19$ & $5(45.5 \%)$ & $6(54.5 \%)$ & $1(---)$ & --- \\
\hline & $20-39$ & $14(37.8 \%)$ & $23(62.2 \%)$ & $0.73(0.19-2.85)$ & 0.65 \\
\hline & $40-64$ & $35(35 \%)$ & $65(65 \%)$ & $0.65(0.18-2.27)$ & 0.50 \\
\hline & $\geq 65$ & $36(41.4 \%)$ & $51(58.6 \%)$ & $0.85(0.24-2.29)$ & 0.80 \\
\hline & $0-20$ & $5(100 \%)$ & $0(0 \%)$ & $1(---)$ & --- \\
\hline & $21-40$ & $25(83.3 \%)$ & $5(16.7 \%)$ & $1.80(0.18-17.75)$ & 0.61 \\
\hline \multirow[t]{5}{*}{ APACHE Score } & $41-60$ & $50(60.2 \%)$ & $33(39.8 \%)$ & $3.0(0.33-26.92)$ & 0.33 \\
\hline & $61-80$ & $39(46.4 \%)$ & $45(53.6 \%)$ & $3.85(0.43-34.68)$ & 0.23 \\
\hline & $81-110$ & $26(78.8 \%)$ & $7(21.2 \%)$ & $3.85(0.42-35.6)$ & 0.24 \\
\hline & $1-7$ & $1(1.5 \%)$ & $68(98.5 \%)$ & $1(---)$ & --- \\
\hline & $8-14$ & $11(19.6 \%)$ & $45(80.4 \%)$ & $16.6(2.1-133.3)^{* *}$ & 0.008 \\
\hline \multirow[t]{3}{*}{ Length of stay (day) } & $15-28$ & $24(53.3 \%)$ & $21(46.7 \%)$ & $77.7(9.9-169.4)^{* *}$ & $<0.001$ \\
\hline & $29-42$ & $28(77.8 \%)$ & $8(22.2 \%)$ & $238(28.4-1992.6)^{* *}$ & $<0.001$ \\
\hline & $>6$ Weeks & $26(89.7 \%)$ & $3(10.3 \%)$ & $589.3(58.6-5924.5)^{* *}$ & $<0.001$ \\
\hline \multicolumn{6}{|l|}{$* * \mathrm{P}$-value $<0.01$} \\
\hline \multicolumn{6}{|c|}{ Table 3. Risk factors for each type of hospital-acquired infections } \\
\hline & & Univariate $\mathrm{m}$ & & Multivariate model & \\
\hline \multicolumn{2}{|l|}{ Variable type } & $\mathrm{OR}(\mathrm{CI}=95 \%)$ & P-value & $\mathrm{OR}(\mathrm{CI}=95 \%)$ & $\mathrm{p}$ \\
\hline \multicolumn{2}{|l|}{ Age } & $1.002(0.99-1.02)$ & 0.82 & --- & --- \\
\hline \multicolumn{2}{|l|}{ Gender } & $1.20(07-2.04)$ & 0.51 & --- & --- \\
\hline \multicolumn{2}{|l|}{ APACHE Score } & $1.01(0.99-1.03)$ & 0.14 & --- & --- \\
\hline \multicolumn{2}{|l|}{ Total length of stay } & $1.12(1.09-1.15)$ & $<0.001$ & $1.12(1.09-1.15)$ & $<0.001$ \\
\hline \multicolumn{2}{|l|}{ ICU Length of stay } & $1.22(1.15-$ & $<0.001$ & --- & --- \\
\hline
\end{tabular}

1.12 times more than the non-infected (Table 3).

\section{Hospital-acquired infection and increased length of hospital stay}

Using regression analysis, it was concluded that having nosocomial infection increases the length of hospital stay up to 25 days. Our results indicated that mean \pm SD length of hospital stay for infected and non-infected patients was $15.8 \pm 17.2$ and $40.8 \pm 19.1$, respectively.

Hospital-acquired infection and increased costs of infected patients

STATA software was used to find the relationship between having nosocomial infection and increased costs of infected patients and to clarify to what extent it increases these costs. Our results showed that the total cost of patients without hospital infection was $2451 \pm 3098$ USD (83 $674480 \pm 105765500$ Rials). On the other hand, the cost for infected patients was $3264 \pm 6078$ USD (207 497500 \pm 111430700 Rials). Therefore, on average, nosocomial infection increases the total cost of patients up to 3627 USD (123823000 Rials).

Relationship between total and capitation charges with severity of disease

Considering the results of regression model using STATA software, it was concluded that capitation charges had no statistically significant correlation with the severity of disease and its indicator (APACHE score).

\section{Discussion}

According to the findings of the present study, there was a significant difference between studied variables (except for age, gender, and severity of disease before hospitalization in ICU) and presence or non-presence of nosocomial infection. In other words, our results indicated that age, gender, and severity of disease (measured by APACHE score) had no effect on incidence of nosocomial infection. On the other hand, as the confounding effects of such variables were controlled by the researchers, the results of this study are statistically reliable. Despite the findings of our study, Askarian et al. indicated that gender can be a risk factor for incidence of hospital-acquired infection, meaning that gender can both decrease or increase the risk of such infections (17). Also, age has been mentioned as a factor that independently increases the risk of nosocomial infection among hospitalized patients (18).

Moreover, the difference between the total length of stay and ICU length of stay as well as the total costs and capitation costs of patients was more significant between case and control groups compared to number of deaths between these groups (Table 1). Therefore, the total length of stay, ICU length of stay, and total costs and capitation charges for infected patients were more than those of noninfected ones. Furthermore, there was an important finding in this table showing that number of deaths in the control group was more than the case group. Although other studies have shown that incidence of nosocomial infection relatively increases the number of deaths among infected patients $(19,20)$, our study results were quite the opposite.

However, one study supported our results regarding the number of deaths among the infected patients. In that study, the incidence of nosocomial infections did not increase the risk of deaths among the infected patients. However, they did not consider all kinds of infections, except blood stream infections. Their results indicated that incidence of blood stream infections did not increase the risk of death among the infected patients $(16,21)$. One reason behind this can lie in paying more attention to and taking more care of infected patients by their families and the medical staff due to their condition. In other words, incidence of nosocomial infections puts them in the center 
of attention. The other reason is that when they are infected, they are either discharged from the hospital (either by doctors' order or self-discharged) or transferred to another hospital.

The number of patients who are hospitalized for a week or fewer days is more than those who stay more than 1 week in the hospital. To control the effect of this factor on the results of the study, patients with fewer days of hospital stay were divided into more subgroups. Overall, the variable of length of hospital stay was divided into 5 groups. The first 2 groups had stayed in the hospital for 1 week, the second 2 groups stayed for 2 weeks, and the last group stayed more than 6 weeks. Considering the length of hospital stay, we can indicate that only this variable was significantly different between the case and control groups. The case group had stayed in the hospital more than the control group, and the incidence of nosocomial infection could prolong the length of hospital stay among the infected patients (P-value $<0.005$, Odds Ratio $>1)$. Although it is concluded that the incidence of nosocomial infection can prolong the length of hospital stay, the factor of time is also important. It is of significant importance to know which of the variables of incidence of hospital infection or length of hospital stay occurs sooner in terms of time, and this can affect our final judgment.

According to the findings of our study, hospital stay, ICU length of stay, and severity of disease at the time of admission to the hospital or ICU were statistically significant factors for incidence of nosocomial infection. However, the odds ratio of these variables could not be statistically dependable. Multivariate regression analysis showed that the more the severity of patients' disease at the admission time and the more their length of hospital stay, the more the possibility of incidence of nosocomial infection. Our results revealed that between length of hospital stay and severity of disease, only the former had a significant correlation with incidence risk of hospital-acquired infection. This shows that the longer the patients stay in the hospital, the more they are in risk of acquiring nosocomial infection.

In response to the question of "How much nosocomial infection can, on average, augment length of hospital stay?" Our results indicated that the non-infected patients had stayed $15.8 \pm 17.2$ days in the hospital, while the infected patients had spent $40.8 \pm 19.1$ days in the hospital. Thus, on average, nosocomial infection had increased length of hospital stay up to 25 days. Nevertheless, if we analyze the regression results between incidence of nosocomial infection (as an independent variable) and length of hospital stay, the regression coefficient for incidence of nosocomial infection would be 25 . This is a crude betacoefficient, but its standardized coefficient is 0.49 $(p<0.001)$. This small standardized coefficient shows a strong relationship, indicating that incidence of nosocomial infection boosts length of stay up to 25 days. This is a mutual relationship, as nosocomial infection increases the length of hospital stay and increased hospital stay raises the risk of getting nosocomial infection.

Adding variables of age, gender, and even APACHE score does not affect the beta-coefficient of nosocomial infection. Therefore, the correlation between nosocomial infections and increased length of stay is not influenced by age, gender, and APACHE score. In other words, incidence of hospital infection independently raises the length of hospital stay without being affected by those background variables. There have been some findings by other studies in support of our study results regarding the effect of nosocomial infection on increased length of hospital stay $(22,23)$. Moreover, in most studies, the number of days added to the patients' hospital stay varied from 3 to 28 days (24-27). Our findings showed that nosocomial infection increases hospital stay up to 25 days.

\section{Conclusion}

As found by the present study, some extra cost (3627 USD) (123 823000 Rials) was imposed on patients due to incidence of hospital infection. One of the drawbacks of Iran's health system, which can also be found in other health systems of developing countries, is that although calculation of unit cost of health services is a difficult job, there is no serious effort and commitment to do it. If the unit cost of health services was available in Iran, we would have been able to calculate the costs of many diseases, and the results of these calculations would have been used in health policy and decision-making. Unfortunately, due to not having these data in the country, no study has been able to calculate the extra costs of nosocomial infections; therefore, the results of the present study cannot be compared to those of other national studies.

\section{Limitations}

-Inaccessibility to medical records of some of the ICU patients

- Inaccessibility to the medical data of some of general ICU patients

\section{Recommendations}

Considering the results of the present study, future researchers should focus on the following topics:

-Studying the direct and indirect effects of hospital infections on patients and the society

-Studying the mental, economic, and physical effects of hospital infections on hospital staff

\section{Acknowledgments}

This article was a part of an M.S thesis at Tehran University of Medical Sciences in 2017. We thank all professors, hospital mangers, and nurses as well as other participants who sincerely helped us during the study.

\section{Conflict of Interests}

The authors declare that they have no competing interests.

\section{References}

1. Azar FE, Asiabar AS. Does leadership effectiveness correlates with leadership styles in healthcare executives of Iran University of Medical Sciences. Med J Islam Repub Iran. 2015;29:166. 
2. Fardazar FE, Safari H, Habibi F, Haghighi FA, Rezapour A. Hospitals' readiness to implement clinical governance. Int J Health Policy Manag. 2015;4(2):69.

3. Rezapour A, Azar FE, Aghdash SA, Tanoomand A, Shokouh SMH, Yousefzadeh N, et al. Measuring equity in household's health care payments (Tehran-Iran 2013): technical points for health policy decision makers. Med J Islam Repub Iran. 2015;29:246.

4. Anderson DJ, Podgorny K, Berríos-Torres SI, Bratzler DW, Dellinger EP, Greene L, et al. Strategies to prevent surgical site infections in acute care hospitals: 2014 update. Infect Control Hosp Epidemiol. 2014;35(S2):S66-S88

5. Goldstein EJ, Johnson S, Maziade P-J, McFarland LV, Trick W, Dresser L, et al. Pathway to prevention of nosocomial Clostridium difficile infection. Clin Infect Dis. 2015;60(suppl_2):S148-S58.

6. Dick AW, Perencevich EN, Pogorzelska-Maziarz M, Zwanziger J, Larson EL, Stone PW. A decade of investment in infection prevention: a cost-effectiveness analysis. Am J Infect Control. 2015;43(1):4-9.

7. Karkhane M, Pourhoseingholi MA, Kimiia Z, Mortazavi SM, Torkabad MRA, Aghdam SKH, et al. Attitudes Toward Nosocomial Infections Associated Mortality at Intensive Care Units, and Evaluation of the Risk Factors. Arch Clin Infect Dis. 2016;11(2).

8. Allegranzi B, Bagheri Nejad S, Chraiti M, Castillejos G, Kilpatrick C, Kelley E. Report on the burden of endemic health care-associated infection worldwide. Geneva, Switzerland: World Health Organization. 2011.

9. Safari H, Ebrahimi E. Using modified similarity multiple criteria decision making technique to rank countries in terms of human development index. J Indus Eng Manag. 2014;7(1):254-75.

10. Lipscomb J, Yabroff KR, Brown ML, Lawrence W, Barnett PG. Health care costing: data, methods, current applications. LWW; 2009.

11. Horan TC, Andrus M, Dudeck MA. CDC/NHSN surveillance definition of health care-associated infection and criteria for specific types of infections in the acute care setting. Am J Infect Control. 2008;36(5):309-32.

12. Rezapoor A, Azar FEF, Safari H, Arabloo J. Cost Analysis of Services Delivered to Patients with End-Stage Renal Disease referring to Bou-Ali-Sina Hospital Affiliated to Qazvin University of Medical Sciences. World Appl Sci J. 2012;18(6):796-802.

13. Pittet D, Allegranzi B, Storr J, Nejad SB, Dziekan G, Leotsakos A, et al. Infection control as a major World Health Organization priority for developing countries. J Hosp Infect. 2008;68(4):285-92.

14. Phu VD, Wertheim HF, Larsson M, Nadjm B, Dinh Q-D, Nilsson LE, et al. Burden of hospital acquired infections and antimicrobial use in Vietnamese adult intensive care units. PloS one 2016;11(1):e0147544.

15. Vincent J-L, Rello J, Marshall J, Silva E, Anzueto A, Martin CD, et al. International study of the prevalence and outcomes of infection in intensive care units. Jama. 2009;302(21):2323-9.

16. Karkhane M, Pourhosiengholi MA, Torkabad MRA, Kimiia Z, Mortazavi SM, Aghdam SKH, et al. Annual Antibiotic Related Economic Burden of Healthcare Associated Infections; a CrossSectional Population Based Study. Iran J Pharm Res: IJPR. 2016;15(2):605

17. Askarian M, Yadollahi M, Assadian O. Point prevalence and risk factors of hospital acquired infections in a cluster of universityaffiliated hospitals in Shiraz, Iran. J Infect Public Health. 2012;5(2):169-76.

18. Tiwari P, Rohit M. Assessment of costs associated with hospitalacquired infections in a private tertiary care hospital in India. Value Health Reg Issues. 2013;2(1):87-91.

19. Lahsaeizadeh S, Jafari H, Askarian M. Healthcare-associated infection in Shiraz, Iran 2004-2005. J Hosp Infect. 2008;69(3):283-7.

20. Vincent J-L, Rello Condomines J, Marshall J, Silva E, Anzueto A, Martin CD, et al. The extended prevalence of infection in the ICU study: EPIC II. JAMA. 2009;302(21):0001-49.

21. Penel N, Lefebvre J-L, Cazin J, Clisant S, Neu J-C, Dervaux B, et al. Additional direct medical costs associated with nosocomial infections after head and neck cancer surgery: a hospital-perspective analysis. Int J Oral Maxillofac Surg. 2008;37(2):135-9.

22. Abbas M, Pittet D. Surgical site infection prevention: a global priority. J Hosp Infect. 2016;93(4):319-22.

23. Thompson J, Jefferson J, Mermel LA. Potential economic impact of hospital-acquired infections in uninsured patients: a preliminary investigation. Infect. Control Hosp. Epidemiol. 2008;29(8):764-6.
24. Nathwani D, Raman G, Sulham K, Gavaghan M, Menon V. Clinical and economic consequences of hospital-acquired resistant and multidrug-resistant Pseudomonas aeruginosa infections: a systematic review and meta-analysis. Antimicrob Resist Infect Control 2014;3(1):32.

25. Vrijens F, Hulstaert F, Van de Sande S, Devriese S, Morales I, Parmentier Y. Hospital-acquired, laboratory-confirmed bloodstream infections: linking national surveillance data to clinical and financial hospital data to estimate increased length of stay and healthcare costs. J Hosp Infect. 2010;75(3):158-62.

26. Raschka S, Dempster L, Bryce E. Health economic evaluation of an infection prevention and control program: are quality and patient safety programs worth the investment? Am J Infect Control. 2013;41(9):773-7.

27. Hu B, Tao L, Rosenthal VD, Liu K, Yun Y, Suo Y, et al. Deviceassociated infection rates, device use, length of stay, and mortality in intensive care units of 4 Chinese hospitals: International Nosocomial Control Consortium findings. Am J Infect Control. 2013;41(4):301-6. 